\title{
La práctica docente en la Licenciatura en Literatura: Diagnóstico. Aportes a una discusión ${ }^{1}$
}

\author{
Preservice Teaching in the Bachelor's Degree Program in Literature: \\ A Diagnosis.Contributions to a Discussion \\ A prática docente na Licenciatura em Literatura: \\ Diagnóstico. Contribuições para uma discussão
}

Mery Cruz-Calvo²

\section{Resumen}

Este artículo presenta resultados parciales de una investigación sobre la práctica docente que adelantan estudiantes de la Licenciatura en Literatura, programa académico de la Universidad del Valle. Su propósito es determinar algunas estructuras o habitus que subyacen a las prácticas pedagógicas desarrolladas en diversas instituciones educativas de la ciudad de Cali, como parte fundamental de su ciclo de formación inicial. Para ello se hace un trabajo de campo desde el enfoque de la investigación cualitativa, utilizando herramientas de la etnografía educativa como: observaciones de clase, entrevistas grupales e informes escritos sobre sus experiencias en el aula de clase. Si bien este trabajo no pretende generalizaciones, apunta a señalar algunos derroteros que contribuyan, desde una investigación de campo, a la discusión actual sobre la formación docente en el país. Entre ellos se destaca la importancia del docente universitario como modelo para futuros licenciados, el papel de las estrategias de intervención al momento de la clase, así como las innovaciones en la didáctica de la literatura, que los practicantes están construyendo.

\section{Palabras clave}

práctica docente; licenciatura en literatura; literatura; habitus; creencias

\section{Abstract}

This paper presents the partial results of an investigation conducted about the preservice teaching of literature students from the academic program of Universidad del Valle. The purpose is to determine certain structures or habitus underlying the pedagogical practices at different educational institutions in Cali, as a fundamental part of their initial training cycle. For this purpose, a fieldwork is carried out from the qualitative research approach, using tools from educational ethnography, such as: class observations, group interviews, and written reports about their experience in the classroom. Although this work is not intended to generalize, it does aim to point out some paths that will contribute, from a field research, to the current discussion about teacher education in the country. The importance of the university professor as a model for future teachers is highlighted, as well as the role of intervention strategies during class, and the innovation in teaching literature that preservice teachers are building.

\section{Keywords}

teaching practice; literature degree; literature; habitus; beliefs

1 Este artículo es uno de los productos de la investigación "La práctica docente en la Licenciatura en Literatura: diagnóstico y líneas de acción", aprobado por la Vicerrectoría de Investigaciones de la Universidad del Valle.

2 Doctora en Didáctica de la Lengua y la Literatura, profesora Asociada de la Escuela de Estudios Literarios, Universidad del Valle, Cali, Colombia, mery.cruz@correounivalle.edu.co. 


\section{Resumo}

0 artigo apresenta os resultados parciais de uma pesquisa sobre la práctica docente desenvolvida por alguns estudantes da Licenciatura em Literatura, programa acadêmico da Universidade do Valle. Seu propósito é determinar algumas estruturas ou habitus que subjazem às práticas pedagógicas desenvolvidas em diversas instituições educativas da cidade de Cali, como parte fundamental do ciclo de formação inicial. Para isso é realizado um trabalho de campo desde a abordagem da pesquisa qualitativa, utilizando ferramentas da etnologia educativa, como: observações de aula, entrevistas grupais e relatórios sobre suas experiências na sala de aula. Ainda que este trabalho não pretende generalizar, visa assinalar algumas rotas que possam contribuir, desde uma pesquisa de campo, à discussão atual sobre a formação docente no país. Entre eles, assinala-se a importância do docente universitário como modelo para futuros professores, o papel das estratégias de intervenção na aula, assim com as inovações na didática da literatura construídas pelos estagiários.

\section{Palavras chave}

prática docente; licenciatura em literatura; habitus; crenças

\section{Artículo recibido el 19 de enero de 2017 y aprobado el 28 de julio de 2017}

\section{Introducción}

El tema de la formación docente cada día ocupa un mayor espacio en los discursos académicos y gubernamentales; en el caso colombiano, en los últimos años asistimos a la publicación y promulgación de documentos que están marcando las agendas de las instituciones que forman educadores. En el balance sobre la Revolución Educativa 2006-2010 se definió el desarrollo profesional de los docentes como una estrategia de la política de mejoramiento de la calidad de la educación, proceso que se construye en la actividad cotidiana de las aulas, espacio de encuentro pedagógico donde docentes $\mathrm{y}$ estudiantes potencian competencias para actuar en los entornos sociales. En esta misma línea, el Ministerio de Educación Nacional (MEN) creó en el 2013 el Sistema Colombiano de Formación, que pretende perfilar egresados que respondan de forma más eficiente a las necesidades y nuevos retos del país (2013, p. 9).

En este contexto también se promulga la Resolución 02041 de febrero 3 de 2016, que establece las características de las licenciaturas en el país para efectos de obtención, modificación o renovación del registro calificado. En otras palabras, se deben hacer cambios estructurales a estos programas académicos, situación que ha generado una gran polémica dentro de las universidades, tanto en los estamentos profesorales como estudiantiles 3 .

3 Véase por ejemplo: Toscano (2016)
Este artículo presenta el diagnóstico realizado de la asignatura Práctica Docente en el programa académico de Licenciatura en Literatura de la Universidad del Valle, por lo cual los documentos mencionados nos implican directamente. Una de las decisiones que ha causado mayor inquietud y rechazo es el mandato de ampliar la práctica pedagógica en la malla curricular, aumentando así el número de créditos presenciales a un mínimo de cincuenta. Cabe resaltar que de acuerdo al documento, las licenciaturas deben garantizar que los futuros docentes vivan estas experiencias con las realidades escolares. No obstante, se pretende llamar la atención sobre lo siguiente: en una lectura atenta de la resolución, se descubre que la denominación y función de esta práctica pedagógica no corresponde estrictamente con la práctica docente, ya que la primera abarcaría a esta última ${ }^{4}$.

Se presentan a continuación algunos de los resultados obtenidos en una investigación de campo con estudiantes de décimo semestre, futuros docentes del área de Lengua y Literatura. Para ello se recogieron datos a través de herramientas de la etnografía educativa, como observaciones de clase, entrevistas grupales e informes finales sobre las prácticas docentes. El propósito principal es determinar qué experiencias son recurrentes en dichas prácticas de los estudiantes y, a la vez, qué estructuras comunes se pueden

4 Dice el documento: “La incorporación de la práctica pedagógica en el plan de estudios debe aumentar a medida que los estudiantes avanzan en su carrera, hasta llegar a la práctica docente en el aula en los períodos finales de la misma" (Men, 2016, p. 10). 
identificar, definir y categorizar como habitus en las actuaciones didácticas de los futuros docentes.

Se considera que el análisis de los datos contribuye al debate sobre la formación inicial (MEN, 2013) que imparte una de las licenciaturas del país, pero también se pretende incorporarse desde la tribuna académica a las discusiones actuales desarrolladas sobre el papel de los docentes en el mejoramiento de la calidad educativa. Lo anterior sin olvidar que este tipo de discusiones alrededor de la formación de los educadores son ante todo un problema político, como muy bien lo expresa María Cristina Davini (1995); para la autora, el asunto responde a dos momentos críticos de la sociedad: ya sea por la insatisfacción que se tiene por los logros de la escuela; ya sea por los cambios políticos que cada Gobierno quiere implementar para dejar su huella en las políticas públicas educativas.

\section{Marco teórico}

\section{La categoría de habitus en Pierre Bourdieu}

La hipótesis de esta investigación se desarrolla en torno a la percepción de cómo realizan la práctica docente los estudiantes de la Licenciatura en Literatura de la Universidad del Valle, los cuales en su mayoría son jóvenes que no tienen ninguna experiencia en el ámbito docente. Como las teorías cognitivas han señalado, es largo el proceso que debe transitar la persona para apropiarse significativamente de saberes, conocimientos y ciertas prácticas sociales y culturales. Lo anterior para destacar que en el pénsum de la Licenciatura en Literatura solo se dedican los dos últimos semestres a la práctica docente, tiempo tal vez insuficiente para la apropiación de los elementos que exige una práctica pedagógica: claridad en los enfoques, didácticas específicas, metodologías, procedimientos de evaluación, conocimiento y familiaridad con la legislación educativa vigente, entre otros.

De tal manera, surgen varios interrogantes: $¿ D e$ dónde van a tomar referentes teóricos y pedagógicos los futuros docentes en el área de Lengua y Literatura para llevar a cabo su práctica docente? ¿Son suficientes las asignaturas del área pedagógica, tales como
Educación, Literatura y Antropología, Teorías del Aprendizaje, Problemática Educativa en Colombia, entre otras? La conjetura del presente artículo es que van a recurrir al aprendizaje adquirido en su vida como estudiantes, a partir del cual han construido conocimientos, pensamientos y creencias sobre lo que debe y no debe hacer un docente. De tal manera, un papel fundamental en este régimen de ideas y creencias será lo que realizan sus profesores en clase, especialmente en el nivel universitario.

Teniendo en cuenta que se pretende identificar, definir y categorizar estructuras comunes a las actuaciones didácticas de estudiantes de una Licenciatura en Literatura a partir de prácticas presenciales, se considera que la categoría de habitus -la cual pertenece al marco explicativo de la teoría de Pierre Bourdieu-permite comprender por qué estos jóvenes se encuentran adelantado sus experiencias pedagógicas de ciertas maneras. A su vez, ofrece aspectos esclarecedores sobre las formas de proceder en situaciones escolares, las concepciones sobre la literatura y sus didácticas que se ponen en juego, y el grado de influencia del pénsum académico en la formación docente.

El habitus es un concepto que tiene antecedentes en Aristóteles cuando se refiere al hexis; Tomás de Aquino y Boeccio lo toman de la tradición aristotélica como término intermedio entre el acto y la potencia: el habitus permite que las personas conviertan sus capacidades latentes en actos verdaderos y realizados. También se refiere a la relación entre lo exterior e interior, es decir, cómo se interioriza el mundo exterior y el pasado con las actuaciones presentes, no de forma mecánica sino dinámica. Otros autores como Husserl y Merleau-Ponty abordan este concepto, pero siempre como percepción y acción individual (Criado, 2009).

El pensador francés Pierre Bourdieu le da a esta categoría una sistematización y dimensión sociológica, mediante la cual pretende superar la dicotomía que establecen las teorías objetivistas que consideran las estructuras sociales como determinantes del comportamiento humano, y las teorías subjetivistas donde todo queda en manos de la voluntad y decisión 
de los individuos. Tales concepciones no conducen a ninguna parte, ya que la primera no explica las diferencias en las actuaciones de personas de un mismo grupo social, mientras que la segunda no da cuenta de las regularidades sociales que escapan a motivaciones individuales. En contraste, para Bourdieu las prácticas sociales son generadas por la relación de dos modos de existencia de lo social:

Por un lado, las estructuras sociales externas, lo social hecho cosas: "campos" de posiciones sociales que se han construido en dinámicas históricas -el sistema escolar, el campo económico, el campo político, etc.-. Por otro lado, las estructuras sociales internalizadas, incorporadas al agente en forma de esquemas de percepción, pensamiento y acción: los habitus. El concepto de habitus servirá, así, para superar la dicotomía entre determinismo objetivista y subjetivismo voluntarista. (Criado, 2009).

Es así como el concepto de habitus se relaciona con patrones de pensamiento y acción interiorizados por personas formadas por $y$ en distintas instituciones, lo cual las lleva a actuar de determinada manera en las diversas situaciones de sus vidas. Bourdieu define el habitus como "sistemas de disposiciones duraderas y transferibles [...] principios generadores y organizadores de prácticas y representaciones" (2007, p. 86). Estos esquemas permiten infinidad de experiencias en distintas situaciones, sin llegar a constituirse en principios explícitos. Dicha categoría da cuenta de la manera en que se vinculan las estructuras sociales y las prácticas individuales (Capdevielle, 2011).

A través de este conjunto de esquemas generativos las personas perciben, su mundo, se apropian de él y actúan en él. Son esquemas estructurados por la sociedad, que los individuos interiorizan de manera particular, según sus historias personales. Aun así, simultáneamente son estructurantes, ya que a partir de ellos se producen los pensamientos, percepciones y acciones de la gente. Es decir, estos esquemas se convierten en la historia de las personas; el habitus es así la historia que deja la huella en el cuerpo o "la historia hecha cuerpo" (Gutiérrez, 1997).
Con la introducción del concepto de habitus, Bourdieu quiere explicar el proceso por el cual lo social se interioriza en los individuos y así señalar las correspondencias entre lo subjetivo y las estructuras objetivas. Las preferencias culturales no operan en un vacío social; por el contrario, dependen de los límites impuestos por las determinaciones objetivas. Por ello, la representación de la realidad y las prácticas de las personas son también y, ante todo, una tarea colectiva.

Desde diferentes reflexiones sobre teorías de la educación se ha llegado a reconocer que el cambio cognitivo en las personas no se da exclusivamente en el interior del sujeto, sino que existe una zona interindividual donde confluyen la historia evolutiva y la situación creada por otros; el aporte principal de esta perspectiva considera el conocimiento como un logro a la vez individual y social (Salas, Román, García y García, 2011). Esto es comprensible si se tiene en cuenta que en comunidades determinadas $\mathrm{y}$ en sus prácticas cotidianas, las personas reciben significados y sentidos que las distintas culturas les ofrecen, se apropian de ellos y producen otros.

Hasta este momento podemos considerar el habitus como una estructura que marca ciertos trayectos vitales, resultado de la negociación que los individuos hacen entre las estructuras sociales y sus subjetividades (en este proceso el campo escolar y educativo desempeña un papel fundamental). Dicho habitus permite -en este caso- a futuros docentes llevar a cabo ciertas experiencias donde se toman decisiones para la mediación didáctica exigida por la formación literaria que reciben los estudiantes de Educación Básica Secundaria y Media.

Los estudiantes de la Licenciatura en Literatura, a partir de su formación disciplinar, interiorizan ciertas estructuras pedagógicas: elección del canon de lecturas, metodologías, formas de evaluación, entre otras, las cuales en su futuro profesional $y$, a veces de manera inconsciente, reproducen y adaptan a sus didácticas. Las primeras observaciones permiten formular la siguiente reflexión: como las asignaturas del área pedagógica no impactan de manera suficiente -por su cantidad e interés- la formación 
de estos futuros docentes, son las asignaturas disciplinares el lugar de donde extraen modelos para los procesos de enseñanza y aprendizaje que llevarán a la práctica en sus posibles lugares de trabajo.

\section{¿Qué debe saber un docente en su formación inicial?}

En gran parte de la bibliografía consultada sobre la práctica docente aparece una temática que es ineludible en un tipo de investigación como la que se propone en este artículo: se trata del pensamiento, el conocimiento y el saber docente. Cabe destacar que este ámbito de indagación ha tenido un desarrollo significativo; es así como desde 1975 se despierta un paulatino interés por lo que los docentes piensan sobre los procesos educativos en general, y las dinámicas de enseñanza y aprendizaje que se adelantan particularmente en el aula, en palabras de Gerardo Andrés Perafán (2002).

Este mismo autor alude a los supuestos básicos sobre el pensamiento de un futuro docente. En primer lugar, se refiere a que el profesor es un sujeto reflexivo: toma decisiones, emite juicios, tiene creencias, genera rutinas en su práctica docente cotidiana. En segundo lugar, considera que el pensamiento del profesor influye y determina sus conductas, lo cual media en las acciones en el aula. Por último, plantea que en la reflexión y el pensamiento docente se dan dos niveles: uno explícito, fácilmente apreciable en las prácticas; otro implícito, más difícil de identificar e interpretar (Perafán, 2002, p.13).

En estas exploraciones sobre el conocimiento de los profesores y el proceso de aprender a enseñar se han desarrollado concepciones de corte psicológico y cognitivo que explican cómo aprende el profesorado. Con relación a tal aspecto cabe recordar que recientemente se ha reconocido a los docentes como sujetos que desarrollan una epistemología sobre sus prácticas (Marcelo, 2002). Los dos primeros enfoques responden a la pregunta de cómo piensa el profesor; el tercero, interroga sobre qué y por qué piensa de esa manera (Perafán, 2002). Desde esta última perspectiva, cada día se da más importancia al conocimiento que se deriva de la práctica; Carlos Marcelo lo caracteriza de la siguiente manera:

Es lo que se ha denominado conocimiento tácito, teorías privadas, teorías implícitas, conocimiento práctico personal, imágenes o simplemente creencias. Este es un tipo de conocimiento más personal, contextualizado, difícil de codificar, moral y emocional, privado e interpersonal, oral, tácito, orientado a soluciones, metafórico, narrativo y en general de poco prestigio. (Marcelo, 2002).

En este punto es importante preguntarse qué es lo más significativo para el estudio llevado a cabo. Desde su formación inicial, el estudiantado de la licenciatura construye conocimientos y creencias sobre cómo, qué y por qué enseñar; estas convicciones van a guiar muchas decisiones pedagógicas y didácticas para llevar a cabo sus prácticas en el aula de clase en cuanto a la formación literaria de sus estudiantes se refiere. El futuro docente es una persona que no solo hace una labor, sino que educa con herramientas como su presencia, palabra y mirada (Pilonieta, 2006). Este repertorio se va edificando en el denominado aprendizaje por observación; en otras palabras, aprende de lo que ve en sus maestros en la universidad, interiorizando referentes que permanecen y funcionan a nivel del inconsciente, por lo cual serán difíciles de remover y reemplazar.

En otros desarrollos sobre las creencias y los saberes docentes, se señala la necesidad de hacer valer la formación pedagógica de los futuros enseñantes; esta reiteración responde a una realidad de las facultades de educación de diversas partes del mundo, ya que en sus currículos dan prioridad a las áreas disciplinares. Es así que el ámbito pedagógico y de las prácticas queda relegado a un segundo plano (Esteve, 2009; Perrenoud, 2006; Pogré, 2007; Vaillant, 2004), y de esta manera se inscribe en la tradición académica del docente, como muy bien lo clasifica María Cristina Davini.

Esta matriz tradicional cuenta con dos características: primero, lo esencial en la formación y acción de los futuros profesores es el conocimiento sólido de la materia que enseñan; segundo, la formación pedagógica es débil, superficial e innecesaria, a la vez 
que obstaculiza la educación de los docentes (Davini, 1995). En este orden de ideas, la tradición formadora no valora el conocimiento pedagógico, considerando que se limita a una cuestión de instrumentación didáctica para aplicar en el aula de clase o de ciertas metodologías o estrategias que pueden solucionar problemas puntuales.

Ante el predominio de dicho enfoque en las instituciones de educación superior, surgen voces que, si bien valoran como necesario el saber disciplinar, señalan la complejidad de las realidades educativas actuales. En otras palabras, se plantea que por parte de la formación inicial es necesario aumentar el desarrollo de competencias profesionales en el ámbito disciplinar y pedagógico. Lo anterior por cuanto la formación en la disciplina no es suficiente para lo que hoy se presenta como el oficio de enseñar. Laura Fumagalli (2000) considera que -en la medida en que son ineludibles las estrategias de intervención en la enseñanza- el conocimiento profesional de los docentes no se limita a lo teórico, aunque tal saber es fundamental en su formación.

En consecuencia, la educación inicial no solo debe proveer a los futuros docentes de una formalización del conocimiento disciplinar, sino de un lugar para los saberes de la experiencia (Molina, Sierra, y Sendra, 2016), la práctica reflexiva (Perrenoud, 2004) y la formación realista (Esteve, 2012). Tales condiciones fomentarán actitudes en los procederes y estructuras de los docentes, lo cual va más allá de movilizar sus fundamentos teóricos y experiencias. Cabe señalar que la postura reflexiva pertenece al campo de las disposiciones interiorizadas para saber hacer, manifestar una curiosidad permanente y distancia crítica de los hechos, a la vez que preservar un deseo y una necesidad de comprender. Por último, se enfatiza en la necesidad de una formación inicial que capacite al futuro docente para "aprender a mantenerse en la pregunta, y en la exploración, más allá de nuestras certezas y de nuestras teorías" (Molina, Sierra, y Sendra, 2016, p. 74).

\section{Metodología}

\section{Análisis e interpretación de los datos}

Se inicia el análisis y la interpretación de los datos con las observaciones de clase realizadas durante 2014 y 2015. Esta elección se justifica por cuanto se considera el método más importante de la etnografía educativa (Woods, 2011), ya que es una forma inicial de contacto o relación con los objetos que se van a estudiar. Pero es necesario triangular la información de las observaciones con otros datos recogidos en las entrevistas a los grupos de estudiantes de Práctica Docente, como también tener en cuenta los informes finales de sus experiencias pedagógicas. La triangulación permite utilizar diferentes fuentes para corroborar o no la información, lo que da facultades para presentar generalizaciones (Barragán y Salman, 2003). Se busca así, aumentar la fortaleza y la calidad de un estudio cualitativo como el que se presenta en este texto.

Para seleccionar los hechos por observar se tomó como guía el diario de campo. Con estas orientaciones se procedió a la observación; el registro de los datos se realizó en dos niveles: ${ }^{5}$ uno descriptivo, donde se consignó en detalle lo observado en la clase; el otro interpretativo-reflexivo, que da cuenta de lo significativo de la sesión. En la tabla 1, se sintetiza el contexto en el cual se realizaron las observaciones:

5 Adaptado de: http://sportilla2.lacoctelera.net/post/2010/04/20/ diario-pedagogico. 
Tabla 1. Contexto de las observaciones

\begin{tabular}{|c|c|c|c|c|}
\hline $\begin{array}{l}\text { Institución } \\
\text { educativa }\end{array}$ & Actores & Procesos & Fecha & $\begin{array}{l}\text { Número de } \\
\text { reconocimiento* }\end{array}$ \\
\hline Divino Salvador & $\begin{array}{l}\text { Estudiantes } \\
\text { de grado } 6 .^{\circ}\end{array}$ & $\begin{array}{l}\text { Taller para elaboración de } \\
\text { guión. Texto base: Don Quijote } \\
\text { sin mancha, de Aníbal Tobón. }\end{array}$ & 5 de noviembre de 2015 & 1 \\
\hline $\begin{array}{l}\text { Instituto Comercial, } \\
\text { Industrial y } \\
\text { Tecnológico }\end{array}$ & \multirow[b]{2}{*}{$\begin{array}{l}\text { Estudiantes } \\
\text { de grado } 8 .^{\circ}\end{array}$} & $\begin{array}{l}\text { Clase magistral: las vanguardias. } \\
\text { Imágenes, canciones, } \\
\text { muestras literarias. }\end{array}$ & 23 de octubre de 2015 & 2 \\
\hline Multipropósito & & $\begin{array}{l}\text { Trabajo con la lírica: símil y } \\
\text { metáfora. Canciones: Juanito } \\
\text { Alimaña, La bala. Uso de } \\
\text { memes. Poema: "Táctica y } \\
\text { estrategia", de Mario Benedetti. }\end{array}$ & 20 de octubre de 2015 & 3 \\
\hline Las Aguas & \multirow{3}{*}{$\begin{array}{l}\text { Estudiantes } \\
\text { de grado } 9 .^{\circ}\end{array}$} & $\begin{array}{l}\text { Trabajo de escritura: composición } \\
\text { de párrafos. En el principio era el } \\
\text { verbo, de Luisa Fernanda Penagos. }\end{array}$ & 23 octubre de 2015 & 4 \\
\hline $\begin{array}{l}\text { Normal Superior } \\
\text { Farallones }\end{array}$ & & $\begin{array}{l}\text { Escritura de cartas: Memoria por } \\
\text { correspondencia, de Emma Reyes. }\end{array}$ & $\begin{array}{l}29 \text { de abril de } 2014 \\
6 \text { de mayo de } 2014 \\
20 \text { de mayo } 2014 \\
21 \text { de mayo de } 2014 \\
9 \text { de junio de } 2014\end{array}$ & 5 \\
\hline Multipropósito & & $\begin{array}{l}\text { Escritura: convertir un texto } \\
\text { en tercera persona en uno } \\
\text { con narrador testigo. }\end{array}$ & $\begin{array}{l}30 \text { de septiembre } \\
\text { de } 2015\end{array}$ & 6 \\
\hline $\begin{array}{l}\text { Liceo Pedagógico } \\
\text { Suroriental }\end{array}$ & \multirow{4}{*}{$\begin{array}{l}\text { Estudiantes de } \\
\text { grado } 10 .^{\circ}\end{array}$} & $\begin{array}{l}\text { Trabajo de lectura. Textos: } \\
\text { "Es que somos muy } \\
\text { pobres", de Juan Rulfo. } \\
\text { Relato de acontecimiento, de } \\
\text { Rubem Fonseca. Ilustración de } \\
\text { Frida Khalo y Felipe Bedoya. }\end{array}$ & $\begin{array}{l}12 \text { de mayo de } 2014 \\
27 \text { de mayo de } 2014\end{array}$ & 7 \\
\hline Divino Salvador & & $\begin{array}{l}\text { Mesa redonda: compartir sobre } \\
\text { escritura de un ensayo acerca de } \\
\text { las consecuencias de los actos } \\
\text { en la vida. Novela: Campo de } \\
\text { fresas de Jordi Sierra i Fabra. }\end{array}$ & $\begin{array}{l}10 \text { de noviembre } \\
\text { de } 2015\end{array}$ & 8 \\
\hline Multipropósito & & $\begin{array}{l}\text { Escritura de textos sobre } \\
\text { momentos de la vida. }\end{array}$ & $\begin{array}{l}12 \text { de noviembre } \\
\text { de } 2015\end{array}$ & 9 \\
\hline Juan Pablo II & & $\begin{array}{l}\text { Trabajo de lectura. Cuento: } \\
\text { "La muerte enamorada", } \\
\text { de Théophile Gautier. }\end{array}$ & 21 de octubre de 2015 & 10 \\
\hline
\end{tabular}




\begin{tabular}{|c|c|c|c|c|}
\hline $\begin{array}{l}\text { Institución } \\
\text { educativa }\end{array}$ & Actores & Procesos & Fecha & $\begin{array}{l}\text { Número de } \\
\text { reconocimiento* }\end{array}$ \\
\hline Multipropósito & \multirow{4}{*}{$\begin{array}{l}\text { Estudiantes de } \\
\text { grado } 11 .^{\circ}\end{array}$} & $\begin{array}{l}\text { Escritura de cartas. Texto: "Bienes } \\
\text { comunes". Poema: "Lo peor } \\
\text { del amor", de Joaquín Sabina. }\end{array}$ & 22 de octubre de 2015 & 11 \\
\hline Liceo Quial & & $\begin{array}{l}\text { Trabajo de lectura: "La } \\
\text { mano", de Elías Canetti. } \\
\text { Video: Montaigne. } \\
\text { Escritura de párrafos sobre } \\
\text { partes del cuerpo. }\end{array}$ & $\begin{array}{l}10 \text { de noviembre } \\
\text { de } 2015\end{array}$ & 12 \\
\hline Coomeva & & $\begin{array}{l}\text { Clase magistral. Tema: } \\
\text { humanismo. Lectura: } \\
\text { "Versión creación". }\end{array}$ & $\begin{array}{l}24 \text { de noviembre } \\
\text { de } 2015\end{array}$ & 13 \\
\hline $\begin{array}{l}\text { Rodrigo Lloreda } \\
\text { Caicedo }\end{array}$ & & $\begin{array}{l}\text { Trabajo de lectura. Cuento: } \\
\text { La metamorfosis, de Franz } \\
\text { Kafka. Minicuentos. Pinturas. }\end{array}$ & 23 de septiembre 2015 & 14 \\
\hline
\end{tabular}

* Número que identifica a cada uno de los practicantes; aparecen en las citas que se hacen en el análisis de los datos.

Para la interpretación de los datos recolectados en las observaciones de clase se tiene presente uno de los objetivos de la investigación: "identificar, definir y categorizar estructuras comunes en la práctica docente de los estudiantes de Licenciatura en Literatura, de manera que se pueda responder a la pregunta: ¿Qué estructuras comunes se pueden identificar, definir y categorizar como habitus en las prácticas docentes de estudiantes de la Licenciatura en Literatura? Los practicantes observados en diferentes contextos escolares desempeñaron el papel de mediadores entre un saber literario y el saber de sus estudiantes; en tal medida, fue necesario que tomaran muchas decisiones respecto a su trabajo en el aula, por ejemplo: a) qué tipo de enfoque pedagógico aplicar para que los procesos de enseñanza fueran efectivos; b) cuáles eran las metodologías que mejor se ajustaban al desarrollo de competencias básicas y específicas del área; c) en el caso de la formación literaria, escoger un canon que construyera -en la medida de lo posible- lectores críticos, pero al mismo tiempo que disfrutaran de las lecturas propuestas.

Seguidamente, se examina cómo organizaron los practicantes su trabajo en el aula a partir de propuestas didácticas que desarrollaban un canon particular de textos, en su mayoría literarios.

\section{En cuanto a las actividades realizadas en las prácticas docentes}

El registro de las observaciones indica que hubo una actividad común en todas las clases: la lectura de textos. Esta se desarrolló en distintas modalidades; por ejemplo, con las lecturas se hicieron ejercicios de anticipación, es decir, predicciones que van perfilando una pre-comprensión de los textos literarios, donde aparentemente se buscaba despertar expectativas lectoras en el estudiantado. En tal sentido su voz fue importante para ir orientando la actividad comprensiva e interpretativa que supone una lectura crítica y estética de dicha tipología textual. También se observa cómo se emplearon las lecturas como elemento de motivación a la clase y de enganche para desarrollar una temática específica. En ambos casos la pregunta que hizo el docente a los estudiantes fue clave en dos sentidos: a) que fuera potente y movilizara los intereses de quienes iban a iniciar o continuar una lectura; b) que se enganchara de manera significativa con las posteriores interpretaciones de los textos literarios. 
De esta manera se comprueba que un número significativo de practicantes utilizó los textos abordados como modelo para producciones escritas de sus estudiantes; en tal sentido, la categoría en su versión completa se denominaría: Lectura de textos con fines de escritura. Ya sea para escribir una carta -donde se usó como modelo el libro de Emma Reyes Memoria por correspondencia-, para elaborar un guión -a partir de la lectura juvenil de Don Quijote sin mancha, de Aníbal Tobón-, redactar textos sobre un momento especial de la vida de los estudiantes -teniendo como punto de partida el relato de literatura juvenil Campos de fresas, de Jordi Sierra i Fabra-, las lecturas tuvieron una funcionalidad en las producciones textuales.

También se evidenciaron formas de apropiación real de la literatura, es decir, una manera de convertir los lenguajes ajenos en propios: más que ejercicios individuales, lo que construyeron algunos practicantes fueron escenarios donde se compartieron argumentos sobre la experiencia de escribir, se realizaron lecturas en pareja sobre vivencias personales, se escribieron guiones conjuntamente, entre otras actividades. De tal manera, leer y escribir literatura, se manifestaron como prácticas sociales que emergen en contextos específicos. Como resultado del trabajo, dos de los practicantes recogieron los escritos de sus estudiantes en fanzines ${ }^{6}$.

Un ejemplo de cómo un estudiante de grado noveno de un colegio rural de la ciudad de Cali vuelve suya la lectura por medio de la escritura, es la manera como asume los primeros fragmentos de un texto de Estanislao Zuleta:

Elogio de la dificultad es un gran texto de superación personal y tiene componentes que te ayudan a mejorar en tu vida. Este escrito comienza hablando acerca de que nosotros las personas siempre estamos pidiendo estar en la comodidad y es algo real que pedimos. También se habló de todo lo que debemos superar en cuanto a nosotros mismos. Este texto nos dejó mucho de qué reflexionar para ser mejores personas. (4)

6 Publicación hecha con pocos medios y de tirada reducida que trata de temas culturales alternativos.
La practicante tomó la decisión de leer solo una parte del texto, ya que comprendió que los estudiantes no tenían ciertas competencias enciclopédicas y repertorio que les permitiera construir el contrato lector con el escrito. Las referencias a figuras como Kant, Dostoievski, Goethe, Marx, además de categorías filosóficas como esencialismo y circunstancialismo, están muy distantes de sus conocimientos; aun así, la practicante enfatizó en que los estudiantes terminaron de leer el texto y la reflexión se llevó a cabo sobre la dificultad y los desafíos de la lectura. Este trabajo fue valorado en tal contexto y realidad; como muy bien expresó un alumno: "Profe, se me quemaron las neuronas", al referirse a la lectura y escritura sobre Elogio de la dificultad.

Por otro lado, en las entrevistas grupales realizadas a los estudiantes de la Licenciatura en Literatura después de terminada su práctica docente, se preguntó sobre el origen del enfoque pedagógico aplicado en las clases dictadas. Los argumentos presentados señalan que aprendieron a enseñar literatura mediante el ejemplo de sus profesores de la licenciatura.

En dicho contexto fue determinante la pasión que sus docentes transmitieron en clase, la cual se expresa a través de la solidez teórica y el humor como estrategia didáctica para capturar la atención. Uno de los practicantes reconoce algo muy importante -que en términos de teorías del conocimiento se interpreta como una explicación sobre cómo se aprende-: no es la información que se da, sino la formación que se inculca para el futuro. Tal afirmación es fundamental para una licenciatura como programa académico de pregrado, la cual está catalogada en un nivel de formación inicial; el practicante plantea:

Para mí es muy importante la solidez teórica y que intente explicar la complejidad de ciertos temas. Es como poner la espuela de la dificultad; el anzuelo de la dificultad estimula, incita a hacerlo. Eso es para mí lo que me gustó de algunos profesores. (2)

Igualmente se dan argumentos que van más allá de lo positivo o negativo que haya sido el modelo docente. Éstos tienen relación con el posicionamiento frente a los textos escritos: "Nos sentimos en un 
lugar seguro, con cosas preparadas y exámenes ya redactados; más seguros que ir a promover otra cosa distinta, no sé... un performance para presentar un texto. Nos hizo sentir bajo control" (7).

Para otro practicante fueron importantes las jornadas de observación de clases desarrolladas en el marco de la asignatura Práctica Docente I; su comentario va en el siguiente sentido:

Para eso están las observaciones, esas cinco sentadas, observando lo que sucedía. Me advirtieron de muchas cosas, de cosas a lo (sic) que los estudiantes están acostumbrados, que yo, si quería tener algo efectivo, no podía cambiar de la noche a la mañana, tales como los conceptos definidos que el profesor les ofrecía, que interiorizaban a través de talleres. (6).

Otra categoría apreciada en las observaciones de clase bien se puede denominar Estrategias de intervención. Estas se dan a partir de aquellas situaciones inesperadas que se presentan continuamente en el aula de clase, y a las que el docente debe dar respuesta de manera rápida y eficiente para mantener el rumbo que se ha propuesto en su planeación del área. Las estrategias estarían dadas por la distancia entre lo planeado y lo que de verdad se pudo realizar. Para analizar tal situación es necesario combinar dos fuentes de datos: por un lado, la observación; por el otro, los informes finales de la práctica docente. A continuación se presentan algunas situaciones didácticas donde fue necesaria la intervención pedagógica; el propósito es profundizar en la respuesta de los practicantes, para lo cual se recogen y analizan casos significativos.

Los estudiantes del grado 11 inician la lectura de La metamorfosis, de Franz Kakfa. Cabe destacar que estos jóvenes no poseen conocimiento alguno de la obra canónica. La lectura se hace en voz alta; cada uno lee un fragmento. El practicante pregunta, por ejemplo: “¿Qué les llevó a pensar el título?”. Tal interrogante desata una nutrida y activa participación en la cual se elaboran anticipaciones; ha sido una pregunta potente porque despierta interés y motivación por la lectura que a continuación se va a realizar. En algún momento se da un inter- cambio a partir de una pregunta que el practicante dirige a un estudiante sobre qué entiende de la lectura; se reproducen algunos apartes:

E: Nada. Yo leo, pero no entiendo nada. Te soy sincero.

Practicante: ¿Nada, en serio? ¿De lo que han leído no has comprendido nada? ¿Todos sufren de amnesia hoy?

E: (risas)

E: (Mujer): Está interesante, todos queremos seguir leyendo. Yo estoy interesada en saber qué es lo que pasa. Interesante para seguirla leyendo. El problema es que... (interrupción) es difícil de comprenderla.

E: (Hombre): Lo que pasa es que ya la estoy entendiendo; ahora que la estoy volviendo a leer más despacio, así como más despacio la estoy entendiendo (¿cómo se dice cuando es algo irreal?). Para mí, en mi opinión como una situación ficticia donde él empieza a envolver demasiado los roles. En unas partes parece que fuera una persona normal y de pronto empieza a ser otra vez el insecto; todo está perfectamente descrito, sino que enreda un poco la lectura.

E (Mujer): A mí me ha parecido interesante y quiero seguir leyendo, quiero saber por qué, si se convirtió, pero lo que pasa es... que es como... confusa (hablan todos al mismo tiempo). Queremos seguir la lectura... más adelante nosotros vamos captando toda la idea de la lectura, pues no es mucho lo que hemos leído y yo hasta aquí solo he entendido que es una persona que al despertarse era un bicho y como que la familia no se ha dado cuenta porque él no ha querido salir de su cuarto.

E: No es que no entendamos, a mí me encanta leer...

Dicen al mismo tiempo: Sigamos leyendo... (14)

A través de estas intervenciones se manifiesta el deseo de los estudiantes de construir el pacto lectornarrativo; se espera que el practicante intervenga para propiciarlo, pero no asume un comportamiento adecuado y los jóvenes lo desbordan con inquietudes que apuntan a la relación entre ficción y realidad. El sentimiento de extrañeza que experimentan ante 
la lectura de La metamorfosis se puede explicar porque es una historia donde lo extraordinario o lo fantástico convive con un universo cotidiano. En contraste, en sus prácticas culturales construyen con mucha naturalidad el contrato lector con libros o series televisivas de corte maravilloso que contienen elementos sobrenaturales.

Más adelante, el practicante proyecta un blog de la revista de minicuentos Ekuóreo, en la cual aparecen textos (hipertextos) de varios autores escritos a partir de La metamorfosis (hipotexto). Esta estrategia de lectura se convierte en una elección acertada por la excelente recepción que desencadena entre los jóvenes, que bien se puede sintetizar en las palabras de uno de ellos: "Me llama la atención $L a$ cucaracha soñadora, ¡qué enredo!”y a continuación con su celular toma una foto a la página. La clase reconoce el trabajo del profesor-practicante brindándole un aplauso.

En esta misma línea de intervención se observa una clase donde se evalúa la escritura de ensayos a partir de la obra Campos de fresas, de Jordi Sierra i Fabra. La practicante organiza a los estudiantes en una mesa redonda. Es llamativo que en el intercambio que mantiene pone énfasis en la estructura y el propósito del ensayo a partir de las observaciones sobre los escritos presentados por los jóvenes. Señala que han realizado muy buenos trabajos; a la vez hace aclaraciones acerca del uso de los signos de puntuación y las tildes. Se evidencia que los estudiantes logran establecer intertextualidades entre la novela y la canción de los Beatles del mismo título (Strawberry Fields Forever). Posteriormente la practicante repasa los tres momentos de la escritura del ensayo: preescritura, escritura y revisión; explica qué se hace en cada uno.

El día de la clase los jóvenes deben entregar un ensayo cuya temática sea las consecuencias de los actos en la vida; para su escritura se han apoyado en textos visuales, literarios y musicales. Uno de los jóvenes comenta que se basó en textos de internet. La practicante observa que en el texto argumentativo es muy importante la citación; de tal manera recalca el propósito de convencer y disuadir al lector de un punto de vista y que para ello es necesario una bibliografía con autoridad. Un estudiante lee su ensayo y al final la practicante resalta el uso del "yo", por medio del cual el emisor se responsabiliza de lo escrito.

Con estas mediaciones la practicante aproxima la teoría de la argumentación a las prácticas de escritura de estudiantes de grado noveno. Dicho saber académico no se traslada de forma teórica sino a partir de las producciones de los jóvenes; es así una aplicación que tiene sentido por cuanto tiene un propósito: argumentar sobre las posibles consecuencias de los actos.

Una situación similar se puede apreciar en una clase de escritura de relatos de vida, cuando la practicante interviene explicando el uso de conectores diferentes a la preposición " $y$ ” como otra posibilidad de unir ideas. La practicante escribe en el tablero y aclara la función de los conectores, especialmente de adición, para lo cual emplea ejemplos. De tal forma pretende que los jóvenes cualifiquen sus escritos construyendo relaciones más complejas entre sus argumentos. En el informe final de la práctica docente se refiere a esta decisión:

En ese segundo momento era necesario introducir la explicación sobre los conectores lógicos, pero no sabía en qué momento realizarlo, pues todos estaban concentrados en la escritura. Por eso aproveché que un estudiante me pidió que leyera su texto para explicar en qué casos podemos valernos de conectores diferentes a la "y", la cual era de mayor uso. (9).

En este punto es necesario remitirse de nuevo a lo planteado por los practicantes respecto a las intervenciones o actuaciones que tuvieron que asumir con la intención de lograr ciertos objetivos. Se puede afirmar que todos y todas ajustaron, cambiaron o remodelaron las propuestas pedagógicas que habían elaborado por medio de una secuencia didáctica, tal como lo dejan consignado en sus informes finales. En estos se encuentra que las realidades del aula les exigieron realizar ajustes durante el desarrollo de la secuencia; una de las practicantes lo sintetiza con la siguiente reflexión: 
Considero que la experiencia docente me permitió comprender la necesidad de modificar la metodología de enseñanza, encontrando una que respondiera a las necesidades que se presentaron a medida que se desarrollaba la clase. Así mismo, me hizo caer en la cuenta de la importancia de plantear una secuencia didáctica flexible donde como docente no me centre en dar la totalidad de los contenidos sin preocuparme de la comprensión de los estudiantes, sino más bien detenerme y modificarla buscando un punto en el cual sean capaces de interiorizar los conocimientos propuestos. (1)

En el discurso de los practicantes estos ajustes obedecen, en primer lugar, al reconocimiento de los intereses de los estudiantes con quienes se llevaron a cabo las prácticas. Los diferentes cambios en la metodología, las lecturas, las tareas, obedecían a lo que se iba evaluando de cada una de las sesiones. Los practicantes consideran que era fundamental, para el buen desarrollo de su propuesta, interesar en los temas o actividades a los jóvenes, como bien se plantea en los siguientes términos:

Es importante señalar que en el proceso que desarrollé en el Liceo Quial esta etapa tuvo dos momentos debido a un juicio errado que cometí al momento de evaluar la pertinencia de la primera secuencia didáctica, de manera que resultó poco oportuna. (12)

En segundo lugar, las transformaciones y adaptaciones que realizaron los practicantes obedecen a una inconformidad que experimentaron porque las dinámicas propuestas no tuvieron las respuestas esperadas. Esto se expresa en reconocer que plantearon un exceso de conceptos o teorías, e igualmente demasiadas actividades para el tiempo del que disponían. En este último caso tuvieron que seleccionar los contenidos y trabajos más significativos para la formación de los jóvenes. A su vez, las contingencias diarias de un aula de clase -tales como llegadas tarde, manejo de la disciplina, uso de aparatos tecnológicos-, son factores que influyeron $y$ a los cuales tuvieron que responder. En tales situaciones no tenían muchos modelos e hicieron lo que consideraron adecuado en cada momento, como bien lo expresa un estudiante en la entrevista grupal:
En la enseñanza de las materias pedagógicas se sigue priorizando mucho la mente, sin tener en cuenta que estaremos en unos contextos donde las personas se expresan con su corporalidad... Es uno de los grandes choques que tiene una persona que no ha estado en un aula de clase: entender que esa corporalidad hay que saberla encauzar, porque si no va a sobrepasar todo lo que hacemos. (7).

\section{En cuanto a la didáctica de la literatura}

Para los practicantes, los textos trabajados en las clases impactaron de diferente manera en la formación de sus estudiantes. Como principales dificultades se reconocen dos situaciones: la primera, que los jóvenes aceptaran las lecturas, que en ocasiones fueron rechazadas; la segunda, elementos externos, como el poco tiempo que no permitió profundizar en los textos. Ambas situaciones se elaboran desde el discurso de los estudiantes de la licenciatura; se toman dos ejemplos que expresan la respuesta de los estudiantes respecto a los textos propuestos, lo cual es la base para elaborar la secuencia didáctica:

Los cuentos, novelas, artículos de diferente contenido, era evidente que los comprendían; sin embargo, al presentar los ensayos y trabajar en su contenido fue algo nuevo para ellos, no sabían cómo manejarlo. A pesar de esto, los jóvenes se estimularon con la participación y la investigación asignada. Esto pasó con el texto de Estanislao Zuleta, ya que lo leímos en voz alta en la clase y en cada párrafo se perdían de la idea principal; por ello fue un texto utilizado varias veces, para que se familiarizaran con tantos temas relacionados fuera de él. (4).

La segunda posición señala:

El mayor reto no fue la escritura; el mayor reto fue hacer que se sintieran interesados por la lectura. Tal vez los relatos de Paul Auster en Creí que Dios era mi padre no eran lo suficientemente cercanos a ellos; en eso fallé. (9).

En el primer caso la practicante persiste en buscar estrategias interpretativas que propiciarán que los jóvenes lectores (as) pudieran acceder al texto y, por ende, aceptaran leerlo. Es importante señalar que, si bien la profesora es estudiante de la licenciatura, ya 
laboraba en el colegio y esto le daba la posibilidad de volver al texto las veces que considerara adecuadas. En contraste, la segunda estudiante solo tuvo las pocas horas que le asignaron para sus clases; en tal medida no logró profundizar en por qué los estudiantes fueron poco receptivos a estos cuentos, a pesar de lo cual logró desarrollar la actividad de escritura autobiográfica. Se debe resaltar la responsabilidad que asume por no haber acertado en la elección del canon a trabajar. A continuación, se presentan otras reflexiones sobre el asunto planteado:

Para motivar la lectura en voz alta y, con esta, la participación del estudiantado, pasé de los textos de más de media página y acogí los minicuentos o microrrelatos. Tuve éxito. Como dice Enrique Vila-Matas, todos quieren leer a Monterroso. (6).

La carta de Murakami les encantó, aunque no les gustó el final de la historia. Los demás textos que llevé también los conectaron bien: es un mito ese que a los adolescentes no les interesa la literatura; a ellos les interesó, era la parte de la clase que más les gustaba. También era la parte en la que creían que no les tocaba hacer nada, ipero vaya! Si supieran lo difícil que es "solo escuchar". (11).

El poema que compartí en clase es "La culpa es de uno", del uruguayo Mario Benedetti, leído por él mismo en un audio con música de fondo. Un poema triste. Por supuesto, las palabras que ellos no entendían las expliqué. Cuando uno de ellos me pidió con cierta distancia que repitiera el poema, y los demás lo apoyaron, me sentí satisfecha. ¡Querían escuchar el poema! ¡Querían entenderlo! Fue el momento más feliz. Escuchaban el poema, cabizbajos, con el ceño fruncido y al final una sonrisa de compasión. "Ay, pobrecito ese man. Se va a matar de la tristeza”. (3).

En estos tres registros recopilados de los informes finales, las experiencias con las lecturas en clase tienen diferentes intensidades para los practicantes. En primer lugar y en pocos renglones, uno de ellos decide cambiar sus lecturas por otras más cortas, más fáciles para los oyentes: los minicuentos. Esta intervención didáctica es evaluada como exitosa, pero tal apreciación tiene un rasgo irónico en el contexto en que es enunciada por el practicante, cuando sin venir mucho al caso escribe: "Como dice Enrique Vila-Matas, todos quieren leer a Monterroso". VilaMatas, como afamado escritor contemporáneo, es una autoridad literaria. En contraste, Monterroso se ha hecho famoso por sus minicuentos; con sus palabras, el estudiante se apoya en la institución literaria para expresar su poco agrado por el género literario al cual, debido a la situación en el aula, ha tenido que recurrir como material de lectura.

Una segunda sistematización de la experiencia de aula reconoce que los estudiantes acogieron de forma positiva las lecturas propuestas; expresiones como "les encantó", "los conectaron bien", así lo evidencian. Llama la atención que las observaciones de este practicante van más allá del aula y se conectan con un pensamiento que desmonta el lugar común o imaginario de jóvenes que no leen o no les gusta la lectura; su práctica le demuestra que esto no es cierto y por el contrario su encuentro fue con personas interesadas en leer los textos y que toman posición crítica frente a estos: "aunque no les gustó el final de la historia". El pensamiento del practicante profundiza en sus reflexiones y valora a sus estudiantes por "escuchar" las lecturas; contrario al anterior practicante, este discurso no ironiza, sino que muestra una posible paradoja en términos cargados de optimismo, cuando comenta que los estudiantes creen que no están haciendo nada al escuchar las lecturas, pero para él están haciendo un gran esfuerzo.

Las palabras de la última practicante están cargadas de gran sorpresa e inmensa satisfacción por la recepción tan emotiva de los jóvenes de grado octavo. En el desarrollo de su secuencia didáctica este es el momento culmen por la receptividad del poema de Mario Benedetti. Es importante señalar que la practicante usa las nuevas tecnologías; -en este caso internet y el servicio que presta YouTube -para un ejercicio de escucha de un poema, que para un grupo de bachillerato puede tener cierto grado de dificultad en cuanto a entender palabras y expresiones retóricas, las cuales la practicante aclara. Sin embargo, se sabe que no es suficiente la comprensión literal para sentir la palabra poética; hace falta un ambiente y es lo que se logra en esta lectura concreta: conectar afecti- 
vamente a los estudiantes con el poema. Ante esta respuesta ya no hay ironía ni paradoja en el discurso que analiza la experiencia; se desborda gradualmente

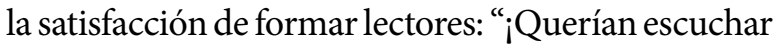
el poema! ¡Querían entenderlo! ¡Fue el momento más feliz!". Los estudiantes se conectan con el sentimiento que les ha transmitido la voz de Benedetti y que ha puesto en escena la docente; es el momento de la literatura por cuanto los jóvenes se apropian del poema y pronuncian una sentencia que no se encuentra en este, sino que es la interpretación que a partir de la palabra poética construyen jóvenes de secundaria de un colegio oficial y que lo expresan con su retórica particular: "Ay, pobrecito ese man. Se va a matar de la tristeza".

De tal manera, los tres ejemplos planteados reflejan diferentes grados de intensidad; con esto se alude a la valoración pedagógica, didáctica y hasta emotiva que construyen de su experiencia en el aula. Se encuentran así prácticas vividas con cierta frustración o desilusión, pasando por la valoración del trabajo de los estudiantes, hasta llegar a una práctica que desborda emoción: la estudiante vive y siente un momento en el cual los alumnos se conectaron profundamente con un texto poético gracias a su mediación. En sus palabras se sintetiza una reflexión profunda sobre una práctica docente concreta, que bien puede valorarse y ser asumida como una declaración de principios para cualquier docente en ejercicio de su profesión. Esta estudiante de la Licenciatura en Literatura manifiesta con su discurso que ser docente es un ejercicio de aprendizaje constante y que es necesario estar alerta y saber interpretar los signos que nos envía el contexto escolar, pero que ante todo se precisa de una educación emocional: ella aprende a ser formadora en la medida que sus alumnos y alumnas se compenetraron con el texto poético que les había presentado.

Creo que compartí con un grupo muy especial que me enseñó que la poesía hace sentir a los más temerarios, que las planeaciones son una base mas no son concluyentes, que siempre debo hacer diagnóstico, que ellos son alegres y yo tengo el deber de aprovechar esa alegría, que nunca debo presumir sobre mis capacidades con un grupo al que no conozco. Me enseñaron que puedo ser obsesiva y al mismo tiempo inteligente con chicos a los que considero mis estudiantes. (3).

\section{Conclusiones}

Al llegar a este punto del trabajo se presentan algunas conclusiones preliminares que irán perfilando el diagnóstico sobre la práctica docente en la Licenciatura en Literatura. Esta primera parte buscaba responder a la pregunta sobre las estructuras que se pueden identificar y que llevan a definir los sustentos teóricos y pedagógicos que se encuentran implícitos en las prácticas docentes de los estudiantes de este programa académico.

Si bien las experiencias pedagógicas ejecutadas por los practicantes en las instituciones escolares se caracterizaron por abordar una variedad de géneros literarios y por las diferentes gamas de actividades, hay un patrón que se identifica y que todos pusieron en práctica, sintetizado en la categoría de Lectura de textos con fines de escritura. Esto se traduce en trabajar primero con la lectura de un texto para luego imitarlo siguiendo su estructura o transformarlo en otro tipo de texto.

Por otro lado, esta estructura o habitus que hemos identificado en el pensamiento pedagógico y la actuación didáctica de los practicantes, se considera desde las teorías del aprendizaje escolar como un proceso denominado modelado. Tal proceso de aprendizaje se deriva del enfoque conductista y consiste en aprender a partir de la observación e imitación de modelos de comportamiento: una persona es capaz de imitar total o parcialmente el comportamiento de otra.

Aunque en el caso de la formación literaria lo que se imita son textos escritos, se puede elaborar una extrapolación, guardando las diferencias. Si bien esta explicación sobre el aprendizaje es de origen conductista, sus consideraciones generales apuntan a una actividad cognitiva alejada de todo mecanicismo, ya que en esta se ven involucrados factores como atención y percepción de propiedades significativas, codificación o reproducción simbólica 
de lo imitado, y motivación para imitar el sujeto, objeto o comportamiento (Martí y Onrubia, 2002).

Siguiendo con estas generalizaciones de los datos analizados, se halla otra estructura o habitus en las prácticas docentes de los estudiantes: se trata de la transformación de textos originales (hipotextos) en otro tipo de escritos (hipertextos) (Mendoza; 2012); esto en el marco de propuestas didácticas que tienen un grado de complejidad por cuanto se elaboran versiones alteradas que exigen en primer lugar la comprensión del texto "en el plano pragmático, sintáctico, semántico y estilístico" (Moreno, 2008, p.: 206). La evaluación sobre tales experiencias por parte de los futuros licenciados fue altamente positiva.

Los discursos de los practicantes en las entrevistas grupales demuestran que toman este modelo o habitus de sus profesores de la carrera de licenciatura. Llama la atención que las prácticas que más impactan a estos jóvenes en formación son las de sus docentes de las áreas disciplinares, mientras que quienes los han formado en el área pedagógica han dejado una menor huella para su futuro quehacer docente. Tales pautas funcionan como derroteros sobre lo que se debe o no se debe hacer en el aula de clase.

Los intercambios en las entrevistas también indican que los futuros licenciados construyen un pensamiento sobre cómo ser o no docentes a partir del modelo del profesor universitario. Sin embargo, esta construcción se lleva a cabo de manera inconsciente; es en el momento de la práctica propiamente dicha cuando se evidencia, y más que reflexionar sobre esta se desarrolla en los espacios escolares en los que se adelantan las clases. Es importante señalar que las entrevistas fueron el momento para que se revelara algo que ellos desconocían: el posible origen de las decisiones y actuaciones en sus experiencias pedagógicas se hizo así explícito, fue un espacio de intercambio, de poner en orden conocimientos desordenados y percepciones dispersas (Borjas, 2003). En tal medida, surgió y se concretó la práctica reflexiva (Perrenoud, 2004) que persigue alejarse de la experiencia inmediata para ir más allá, elaborando generalizaciones y categorías que bien pueden ser aplicadas a campos de la investigación cercanos al ámbito que se está estudiando, en el presente caso las prácticas docentes y las didácticas específicas.

Continuando con las categorías construidas a partir de los datos analizados en cuanto a las estrategias de intervención a las que tuvieron que acudir los practicantes, se encuentra que en ocasiones se logró dar una respuesta efectiva que garantizó la continuación de la clase y el aprendizaje significativo; incluso se destaca que estas mediaciones potenciaron competencias de los estudiantes.

No obstante, algunos practicantes manifestaron dificultades para intervenir didácticamente de forma oportuna frente a las contingencias que se les presentaron; en consecuencia, desaprovecharon momentos clave para la formación literaria de los aprendices. Por lo anterior, reclaman en sus discursos una mayor educación pedagógica en la licenciatura, por ejemplo, en lo relacionado con el manejo de la disciplina escolar, que puede llegar a entorpecer de manera definitiva lo planeado para la clase. Esta conclusión es un aporte para tener en cuenta en las líneas de acción que se desarrollarán más adelante.

En el análisis sobre el Canon de lecturas se observa la influencia que las diferentes áreas disciplinares han tenido sobre la formación de los practicantes: no se trata solo de abordar el género narrativo -en sus formatos de cuentos, historias de vida, crónicas-, sino de recurrir a otro tipo de textos de la cultura y el arte, tales como cine, video, música, pintura, páginas de internet. En otras palabras, la lectura y la escritura se exponen como prácticas multimodales que envían mensajes compuestos por más de un canal de comunicación (texto escrito, imagen, música) (Lirola y Castejón, 2015), por lo cual se puede pensar que estos jóvenes en su formación pedagógica inicial están mostrando cómo la escuela puede reubicarse en el escenario cultural actual y, desde tal lugar, orientar los movimientos de las nuevas generaciones (Brito, 2010).

Este primer acercamiento a partir de una investigación cualitativa de las prácticas pedagógicas llevadas a cabo por estudiantes de una licenciatura otorga legitimidad para afirmar que se están implementando experiencias significativas, cuyo origen 
se encuentra en la formación inicial que actualmente entrega la Licenciatura en Literatura. Sin embargo, lo anterior no exime de establecer líneas de acción para el mejoramiento del programa académico en general y de las prácticas en particular. Se desea cerrar el artículo resaltando las innovaciones en la educación literaria que estos futuros docentes se encuentran desarrollando con el uso y aplicación de las Tic y la incorporación de las expresiones de las culturas populares y juveniles a sus propuestas didácticas.

\section{Referencias}

Barragán, R. y Salman, T. (2003). Perspectivas sobre la validez, credibilidad y confiabilidad de las investigaciones cualitativas. En R. Barragán (coord.), Guía para la formulación y ejecución de proyectos de investigación (pp. 99-102). La Paz: Fundación PIEB.

Borjas, B. (2003). Metodología para sistematizar prácticas educativas. Por las ciudades de Italo Calvino. Caracas: Federación Internacional de Fe y Alegría.

Bourdieu, P. (2007). El sentido práctico (Primera ed.). Buenos Aires: Siglo XXI.

Brito, A. (2010). Sentires y decires pedagógicos sobre la enseñanza del leer y escribir. En :

Brito (Dir.). Lectura, escritura y educación. Rosario: Homo Sapiens.

Capdevielle, J. (2011). El concepto de Habitus: “con Bourdieu y contra Bourdieu”. Anduli-Revista Andaluza de Ciencias Sociales, 10, 31-45.

Criado, E. (2009). Diccionario crítico de las Ciencias Sociales. Recuperado de https://pendientedemigracion.ucm.es/info/eurotheo/diccionario/H/habitus.

Davini, M. C. (1995). La formación docente en cuestión: política y pedagogía. Buenos Aires: Paidós.

Esteve, J. M. (2009). Políticas de formación inicial y continua (maestros y secundaria). Críticas y propuestas. En B. Puelles (coord.). Profesión y vocación docente. Presente y futuro. Madrid: Biblioteca Nueva.

Fumagalli, L. (2000). Alternativas para superar la fragmentación curricular en la educación secundaria a partir de la formación de los docentes. En C. Braslavski, I. Dussel, P. Scaliter, (eds.). Los formadores de jóvenes en América Latina. Desafíos, experiencias y propuestas. Montevideo: Oficina Internacional de Educación Pública.
Gutiérrez, A. (1997). Pierre, Bourdieu. Las prácticas sociales. Córdoba: Universidad Nacional de Misiones. Universidad Nacional de Córdoba.

Lirola, M. y Castejón, L. (2015). Aprendiendo con textos multimodales: una experiencia práctica en clases de máster. Ponencia presentado durante las XIII Jornadas de Redes de Investigación en Docencia Universitaria: Nuevas estrategias organizativas y metodológicas en la formación universitaria para responder a la necesidad de adaptación y cambio (pp. 908-920). Universidad de Alicante.

Marcelo, C. (2002). La investigación sobre el conocimiento de los profesores y el proceso de aprender a enseñar. Una revisión personal. En G. Perafán y A. AdúrizBravo. (comp.). Pensamiento y conocimiento de los profesores. Debate y perspectivas internacionales. Bogotá: Universidad Pedagógica Nacional. Colciencias.

Martí, E. y Onrubia, J. (2002). Las teorías del aprendizaje escolar. Barcelona: UOC Papers.

Mendoza, A. (2012). Leer hipertextos de papel: sobre el lector y sus hipervínculos cognitivos. En A. Mendoza. Leer hipertextos. Del marco hipertextual a la formación del lector literario. Barcelona: Octaedro.

Ministerio de Educación Nacional (12 de diciembre de 2013). Sistema Colombiano de Formación de Educadores y Lineamientos de Política. Recuperado de: www.mineducacion.gov.co

Ministerio de Educación Nacional (3 de febrero de 2016). Recuperado de: http://www.mineducacion.gov. co/1759/w3-article-356144.html

Molina, M., Sierra, J. y Sendra, C. (12 de diciembre de 2016). Saberes docentes y educación infantil. Notas pedagógicas para la formación inicial. Revista Iberoamericana de Educación. Recuperado de http: www.rieoei.org

Perafán, G. (2002). La investigación acerca de los procesos de pensamiento de los docentes. Orígenes y desarrollo. En G. A. Perafán y A. Adúriz-Bravo, (comp.). Pensamiento y conocimiento de los profesores. Debate y perspectivas internacionales. Bogotá: Universidad Pedagógica Nacional, Colciencias.

Perrenoud, P. (2004). Desarrollar la práctica reflexiva en el oficio de enseñar. Profesionalización y razón pedagógica. Barcelona: Graó.

Pilonieta, G. (2006). Evaluación de competencias profesionales básicas del docente. Estrategia efectiva. Bogotá: Cooperativa Editorial Magisterio. 
Pogré, P. (2007). El desafío de formar profesores para la escuela media. Una propuesta multidisciplinar. En R. Cuenca, N. Nucinkis, y V. Zavala, (comp.). Nuevos maestros para América Latina. Madrid: Morata.

Salas, F., Román, R., García, V. y García, J. (2011). Teoría de la educación en la sociedad de la información y el conocimiento. En Muñoz, J. (Coord.). Temas relevantes en teoría de la educación. Salamanca: Aquilafuente.
Toscano (2016). Algunas claridades sobre el "Revolcón” a las licenciaturas. Recuperado de: http://www.las2orillas.co/ algunas-claridades-revolcon-las-licenciaturas/

Vaillant, D. (2004). Construcción de la profesión docente en América Latina. Tendencias, temas y debates. Chile: PREAL.

Woods, P. (2011). La escuela por dentro. La etnografía en la investigación educativa. Madrid: Paidós. 